\title{
Environmental assessment of solid state recycling routes for aluminium alloys: Can solid state processes significantly reduce the environmental impact of aluminium recycling?
}

\author{
Joost R. Duflou $(1)^{a, *}, A$. Erman Tekkaya $(1)^{b}$, Matthias Haase ${ }^{b}$, Torgeir Welo ${ }^{c}$, \\ Kim Vanmeensel ${ }^{\mathrm{d}}$, Karel Kellens ${ }^{\mathrm{a}}$, Wim Dewulf $(2)^{\mathrm{a}}$, Dimos Paraskevas ${ }^{\mathrm{a}}$ \\ ${ }^{a}$ KU Leuven, Department of Mechanical Engineering, Celestijnenlaan 300A, B-3001 Heverlee, Belgium \\ b TU Dortmund University, Institute of Forming Technology and Lightweight Construction, Baroper Straße 303, D-44227 Dortmund, Germany \\ ${ }^{\mathrm{C}}$ NTNU - Department of Engineering Design and Materials, Richard Birkelandsvei 2B, N-7491 Trondheim, Norway \\ ${ }^{\mathrm{d}} \mathrm{KU}$ Leuven, Department of Materials Engineering, Kasteelpark Arenberg 44, B-3001 Heverlee, Belgium
}

A R T I C L E I NFO

\section{Keywords:}

Recycling

Aluminium

Solid state

\begin{abstract}
A B S T R A C T
Solid state recycling techniques allow the manufacture of high density aluminium alloy parts directly from production scrap. In this paper the environmental impacts associated with 'meltless' scrap processing routes based on three different techniques, namely hot extrusion, screw extrusion and spark plasma sintering (SPS), are compared with the corresponding remelting route as reference. Analysis of the obtained results allows clear conclusions on the perspectives offered by solid state recycling for systematic environmental impact reduction of aluminium recycling with material and energy savings as most important influencing factors. An overall impact reduction with a factor 2 for the SPS route and 3-4 for the extrusion routes is found to be realistic.
\end{abstract}

\section{Introduction}

Various phenomena causing environmental impact are associated with recycling light metals. During the smelting process considerable amounts of energy are required and metal losses occur [1]. Depending on the available input streams and the targeted output alloy, dilution of impurities with higher purity alloys or primary metals may be required and/or quality losses have to be taken into account [2]. In recent years a considerable interest can be observed in recycling aluminium scrap at temperatures below solidus. 'Meltless' processes, more commonly denoted as solid state recycling, can offer significant environmental benefits in terms of energy and materials savings. The target of this article is to document the potential environmental impact reductions that such solid state recycling routes can achieve for aluminium production scrap in comparison to conventional remelting based procedures.

\subsection{Context}

The final remelting step in aluminium recycling is an energy intensive treatment, although favourable compared to virgin aluminium production [3]. Energy savings result from by-passing

\footnotetext{
* Corresponding author.

E-mail address: joost.duflou@mech.kuleuven.be (J.R. Duflou).
}

this remelting step by recycling relatively pure production scrap streams directly into billets or semi-finished products at lower temperatures. Moreover, in this way significant metal savings can be achieved by avoiding some of the intermediate metal losses. For aluminium up to $41 \%$ of the material stream goes into recycling before ever serving as a functional component [4]. These losses depend on the scrap input, the melt treatment, the furnace technology and the material efficiency of the forming processes. Process scrap can typically be retrieved in an additional recycling loop. In contrast, oxidation losses that occur during smelting, also referred to as metal losses, cannot be recovered as the metal property is lost. The 2012 global aluminium mass flow shows average values of $3.7 \%$ for 2012 and $5.4 \%$ for 2013 (forecast) as metal losses after remelting [5]. Especially light gauge aluminium scrap, like chips from material removal processes, results in much higher metal losses. Due to its high surface-to-mass ratio, this fraction tends to float in the melt, leading to losses of up to $16 \%$ with a flux treatment [6] or even up to $20-25 \%$ otherwise [7].

\subsection{State of the art in solid state recycling}

Besides remelting, recent literature reveals also some potential meltless recycling routes in which aluminium alloys are undergoing severe plastic deformation at temperatures below solidus. To be effective the plastic deformation should be large enough to fracture the always-present surface oxide layers that inhibit the metal-metal bonding. Cooper and Allwood [8] presented a model 
on solid state aluminium welding, analysing the influence of deformation conditions on the weld strength.

Direct recycling of machining chips by means of hot extrusion was patented by Stern in 1945 [9], and has recently been demonstrated to allow high quality output if appropriate die design and process parameter control are respected [10-12]. Haase et al. [12] integrated equal channel angular pressing (ECAP) into a hot extrusion die for processing chips, introducing additional strain and shear deformation through the ECAP turns. Utilizing complex deformation routes (porthole and ECAP die-sets), direct recycling by hot extrusion provides comparable or better mechanical properties compared to cast based profiles.

Screw extrusion has been tested as a continuous variant in which the scrap pre-compaction step as well as scrap preheating can be avoided [13]. More recently spark plasma sintering (SPS) has been demonstrated as a solid state recycling technique for scrap consolidation [14]. Dynamic scrap compaction, combined with pulsed electric current joule heating, cleans and activates the metallic surfaces and achieves efficient fracture of the stable surface oxides and desorption of the entrapped gases, resulting in void-less material. Fig. 1 shows examples of scrap consolidation for the presented solid state forming techniques.

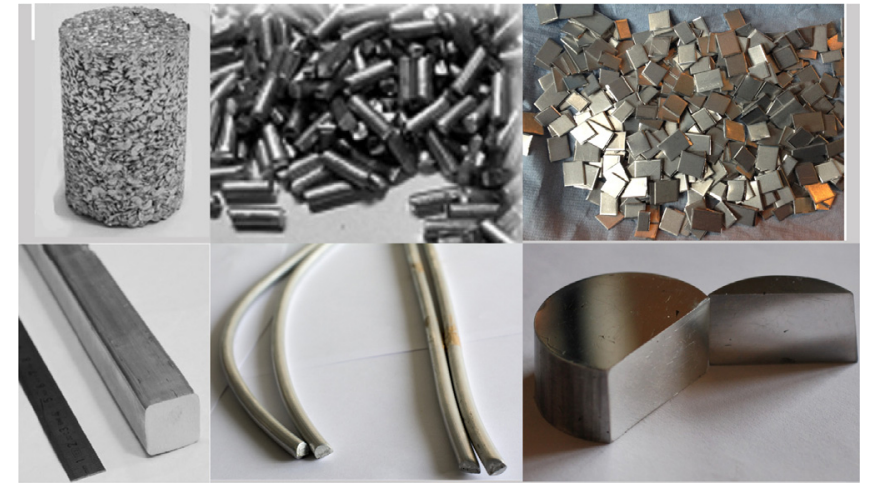

Fig. 1. Scrap input (up) and fully dense profiles and near-net shape semi-finished products (down) obtained from the ECAP hot extrusion, screw extrusion and SPS processes respectively.

\subsection{Objective}

The environmental benefits of solid state recycling techniques listed above have not been analysed in detail yet. This paper contains the results of an extensive comparative LCA study, quantifying three technically explored 'meltless' recycling techniques for aluminium production scrap. Recycling by means of ECAP hot extrusion, screw extrusion and SPS have been compared with the corresponding conventional remelting routes.

\section{LCA methodology and scope definition}

Since a comparative LCA study was targeted and the studied solid state forming processes have different primary shape generation capabilities, two different references for comparison were chosen: for the assessment of direct recycling via hot extrusion and screw extrusion, a $1 \mathrm{~kg}$ profile obtained by extrusion after remelting was used, while for the SPS process $1 \mathrm{~kg}$ of raw material in prismatic near net shape form was compared to a billet of the same weight obtained after remelting. In terms of functional equivalence, the material properties obtained by the respective solid state recycling processes, as partially reported in [10-14] and summarized in Table 1, allow to conclude that the incorporation of the aluminium oxides present in the production scrap into the recyclates does not negatively affect the functional performance of the obtained materials if dispersion or breakage of these oxides layers during the solid state processing can be assured. It can be observed that the resulting materials in some cases show improved property values. Depending on the application this could result in a reduced material demand. New application opportunities can also
Table 1

Mechanical material properties for semi-finished products obtained by three solid state recycling routes compared to their respective reference products (values between brackets).

\begin{tabular}{|c|c|c|c|}
\hline $\begin{array}{l}\text { Mechanical } \\
\text { properties }\end{array}$ & $\begin{array}{l}\text { SPS AA6061 } \\
\text { (ref.: } \\
\text { AA6061 cast) }\end{array}$ & $\begin{array}{l}\text { Screw } \\
\text { extrusion } \\
\text { AA6060 } \\
\text { (ref.: } \\
\text { conventional } \\
\text { extrusion } \\
\text { AA6060 } \\
\text { cast) }\end{array}$ & $\begin{array}{l}\text { ECAP extrusion } \\
\text { AA6060 } \\
\text { as extruded - F } \\
\text { (ref.: ECAP } \\
\text { extrusion } \\
\text { AA6060 cast) }\end{array}$ \\
\hline $\begin{array}{l}\text { State/temper } \\
\text { (ref. state) }\end{array}$ & $\begin{array}{l}\text { Quenched } \\
\text { and } \\
\text { artificially } \\
\text { aged - T5, } \\
\left({ }^{\mathrm{a}} \mathrm{T} 4,{ }^{\mathrm{b}} \mathrm{T} 1\right)\end{array}$ & $\begin{array}{l}\text { As extruded - F } \\
\text { (as extruded - F) }\end{array}$ & $\begin{array}{l}\text { As extruded }-F \\
\text { (as extruded }-F \text { ) }\end{array}$ \\
\hline Hardness [MPa] & $\begin{array}{l}780 \pm 14.7 \\
\left({ }^{a} 652-720\right)\end{array}$ & $340(300)$ & $\begin{array}{l}432 \pm 39 \\
(402 \pm 17)\end{array}$ \\
\hline E-modulus [GPa] & $\begin{array}{l}78 \pm 0.9 \\
\left({ }^{\mathrm{a}} 68-71.5\right)\end{array}$ & - & $71 \pm 1(71 \pm 1)$ \\
\hline $\begin{array}{l}\text { Compressive } \\
\text { strength at } \\
9 \% \text { strain }[\mathrm{MPa}]\end{array}$ & $\begin{array}{l}337 \pm 14 \\
\left({ }^{\mathrm{b}} 256\right)\end{array}$ & - & $\begin{array}{l}146 \pm 10 \\
(149 \pm 15)\end{array}$ \\
\hline $\begin{array}{l}\text { Ultimate tensile } \\
\text { strength [MPa] }\end{array}$ & - & $165(135)$ & $166 \pm 4(168 \pm 2)$ \\
\hline $\begin{array}{l}\sigma_{y} \text { yield stress } \\
{[\mathrm{MPa}]}\end{array}$ & $\begin{array}{l}{ }^{\mathrm{c}} 155-200 \\
\left({ }^{\mathrm{c}} 103-124\right) \\
\end{array}$ & $85(75)$ & $64 \pm 1(65 \pm 1)$ \\
\hline
\end{tabular}

be envisaged. For the purpose of this comparative study, such scenarios are not assumed.

The study was conducted using the ReCiPe Europe H/A method $[15]$ and $\operatorname{Simapro}^{\odot}$ 8.0.2. The endpoint level was selected as a basis for comparison as the impact of all midpoint categories is aggregated into a single unit (Pt). At midpoint level the level of detail is higher: these midpoint results are available upon request. The covered process steps for the different recycling routes are shown in Fig. 2, with indication of the mass fluxes corresponding to the chosen comparison bases. Homogenisation of the material is considered for the chips to obtain homogenous mechanical properties of the aluminium after machining. Chemical degreasing and drying as well as scrap cold compaction were also taken into account. According to the European Aluminium Association (EAA), for the $\mathrm{Al}$ extrusion production $1.324 \mathrm{~kg}$ of $\mathrm{Al}$ ingot is required to obtain $1 \mathrm{~kg}$ of finished extruded product due to the low efficiency of the forming processes [3]. Thus the same amount of material input has been considered for the hot extrusion routes. The extrusion scrap recycling is considered outside the system boundaries.

The substitution methodology, recommended by the EAA [3], is followed in this LCA study to balance the un-recovered metal losses. Consequently, metal losses need to be balanced with primary Al. This approach is valid since the availability of aluminium scrap is limited and the demand exceeds the offering [5]. This picture is not expected to change over the coming decade [5]. As proxy alloy in order to quantify material losses, primary AA6061, a broadly used wrought alloy from the Al-Mg-Si series, was modelled. The concentration of its main alloying elements was assumed to be in the middle of the alloy tolerance interval.

\section{Life cycle inventory}

Where available the impacts associated with well-documented processes, like primary aluminium production, were obtained from the Ecoinvent 2.2 database [17]. The medium voltage electricity mix (global average) for the aluminium industry was used [17]. A closed alloy AA6061 recycling loop was considered for all the routes, avoiding down-cycling or compositional corrections during melting. The Mg content of the scrap is expected to become half or less after remelting [18]. In contrast the concentration of the other alloying elements will not significantly change as these remain in the metal phase. An addition of $0.41 \mathrm{wt} . \%$ of $\mathrm{Mg}$ (nearly half of the 


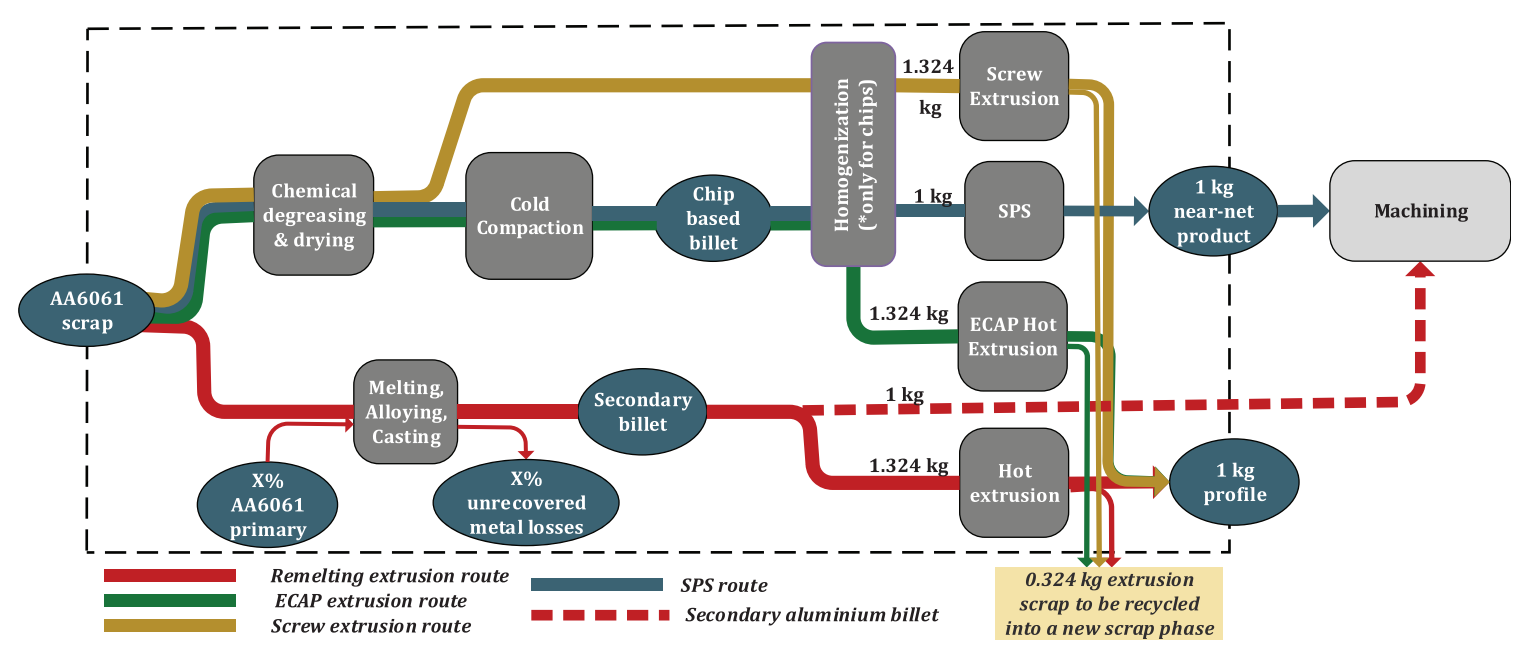

Fig. 2. System boundary of the LCA comparison for the different recycling routes.

Table 2

Screw extrusion settings and measurements.

\begin{tabular}{lll}
\hline & Setting \#1 & Setting \#2 \\
\hline Screw speed & $10 \mathrm{RPM}$ & $12 \mathrm{RPM}$ \\
Feed rate & $\pm 0.70 \mathrm{~kg} / \mathrm{min}$ & $\pm 0.85 \mathrm{~kg} / \mathrm{min}$ \\
Electric power extrusion process & $14.7 \mathrm{~kW}$ & $17.5 \mathrm{~kW}$ \\
Electric power induction heating & $1.56 \mathrm{~kW}$ & $0.09 \mathrm{~kW}$ \\
Compressed air consumption (6 bar) & $9.2 \mathrm{~m}^{3} / \mathrm{h}$ & $36.0 \mathrm{~m}^{3} / \mathrm{h}$ \\
Pre-heating & $5.5 \mathrm{~kW}(40$ min per production day) \\
\hline
\end{tabular}

AA6XXX series average Mg content) was included to compensate the $\mathrm{Mg}$ loss.

Specific data collected for AA6082 (proxy for AA 6061) by observing the experimental screw extrusion set-up are included in Table 2. Measurements were performed for two different process parameter settings. An average value for the energy consumption per unit mass of extruded profile is $0.35 \mathrm{kWh} / \mathrm{kg}$ and the compressed gas consumption is $0.46 \mathrm{~m}^{3} / \mathrm{kg}$.

Regarding SPS, for a sintering cycle with a graphite die of $\varnothing 56 \mathrm{~mm}$ and $56 \mathrm{~mm}$ height, the following energy consumption was measured: (i) vacuum step: $0.205 \mathrm{kWh}$, (ii) heating up to $450{ }^{\circ} \mathrm{C}$ with a constant $5 \mathrm{kN}$ pressure: $0.387 \mathrm{kWh}$ and (iii) dwell segment at $480{ }^{\circ} \mathrm{C}$ and $35 \mathrm{kN}$ load for $3 \mathrm{~min}$ : $0.715 \mathrm{kWh}$. The

Table 3

Materials and processes together with their main LCI data and sources.

\begin{tabular}{|c|c|c|}
\hline Process & Source & Comments \\
\hline $\begin{array}{l}\text { Chemical } \\
\text { degreasing and } \\
\text { drying }\end{array}$ & {$[17]$} & $\begin{array}{l}\text { The dataset encompasses the energy } \\
\text { consumption as well as operating materials } \\
\text { needed to operate degreasing baths. Softening } \\
\text { of the water is included. An average value of } \\
\text { surface to volume ratio of } 1 \mathrm{~m}^{2} / \mathrm{kg} \text { was used. }\end{array}$ \\
\hline Cold compaction & [19] & $0.83 \mathrm{kWh} / \mathrm{kg}$ as compaction energy. \\
\hline Homogenisation & {$[4]$} & $1.4 \mathrm{MJ} / \mathrm{kg}$ natural gas burned in furnace. \\
\hline $\begin{array}{l}\text { Screw extrusion } \\
\text { process }\end{array}$ & & $\begin{array}{l}\text { Average measured energy and compressed air } \\
\text { consumption per unit mass (Table } 2 \text { ). }\end{array}$ \\
\hline Hot extrusion & [3] & $\begin{array}{l}\text { Sawing, scalping, preheating, extrusion, } \\
\text { stretching and ageing are included. }\end{array}$ \\
\hline $\begin{array}{l}\text { ECAP extrusion } \\
\text { chip-based billet }\end{array}$ & {$[3,12]$} & $\begin{array}{l}\text { Same dataset as direct hot extrusion with } \\
\text { additionally } 0.194 \mathrm{kWh} / \mathrm{kg} \text { of electricity for } \\
\text { the ECAP deformation route. }\end{array}$ \\
\hline SPS & & $\begin{array}{l}\text { Measured energy consumption per unit mass, } \\
\text { including insulation graphite paper. }\end{array}$ \\
\hline $\begin{array}{l}\text { Secondary Al } \\
\text { production from } \\
\text { new scrap }\end{array}$ & [17] & $\begin{array}{l}\text { Melting, casting and dross recycling are } \\
\text { included. The loss of Mg as alloying element } \\
\text { is also included. }\end{array}$ \\
\hline Primary AA6061 & [17] & $\begin{array}{l}\text { Concentration of alloying elements in the } \\
\text { middle of the alloy tolerance limits. }\end{array}$ \\
\hline $\begin{array}{l}\text { Alloying elements } \\
(\mathrm{Cu}, \mathrm{Si}, \mathrm{Mg}, \mathrm{Mn})\end{array}$ & [17] & $\begin{array}{l}\text { Resource extraction until the gate of the } \\
\text { factory including infrastructure. }\end{array}$ \\
\hline Electricity & [17] & $\begin{array}{l}\text { Medium voltage electricity for the aluminium } \\
\text { industry, global. }\end{array}$ \\
\hline
\end{tabular}

standby mode consumes around $2 \mathrm{~kW}$. Bypassing the vacuum step that is not required, the total energy consumption per mass for this cycle is calculated to be $2.96 \mathrm{kWh} / \mathrm{kg}$.

For the hot extrusion process the EAA environmental report [3] was used as primary LCI source, as it covers a full set of subprocesses (see Table 3). The same dataset was used also for the ECAP hot extrusion, taking into account an additional amount of energy required for the ECAP deformation route compared with the conventional die. The sources used to further document the covered unit processes are listed in Table 3.

\section{Impact assessment results and discussion}

Fig. 3 shows the endpoint scores for the respective recycling routes with a breakdown according to the consecutive process steps. A sensitivity analysis was conducted to assess the influence of the nature of the scrap material and possible pre-processing techniques used before remelting. As discussed in the introduction, un-recoverable losses can vary depending on the scrap type and melt treatment, ranging from $4 \%$ up to $16 \%$ or even $20 \%$ for light gauge scrap [5-7]. Industrial research partners indicated that these numbers are close to their observed efficiency, with $10 \%$ of metal losses as a minimum value for fine form aluminium scrap. Pre-compaction of scrap with a high surface to volume ratio can reduce the material losses significantly [7], but, for example, $9-10 \%$ remains a lower boundary value for chips. The sensitivity of the

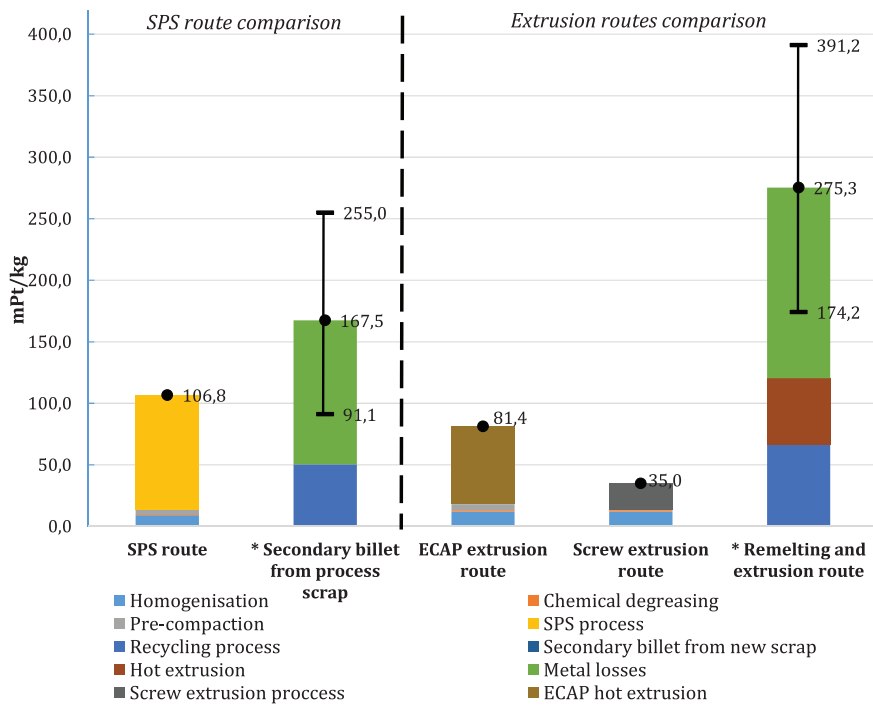

Fig. 3. Environmental impact contribution of all processes involved according to ReCiPe endpoint Europe H/A LCIA method. *4-16\% metal losses during remelting balanced with primary AA6061. 
LCA results for the effective metal losses is illustrated by the uncertainty margins included in Fig. 3, corresponding to 4\% (for most of the scrap categories) and 16\% (representative for light gauge scrap) of unrecovered metal losses for the lower and upper impact results, respectively, and a medium scenario of $10 \%$ metal losses.

From Fig. 3 it can be observed that the major avoided impact results from the elimination of material losses in the solid state recycling routes. The sensitivity analysis clearly illustrates that the benefits of solid state recycling are most outspoken for light gauge production scrap resulting in high material losses during remelting. This typically includes foil scrap, chips, turnings and powderous materials. In a market situation where these losses would not be compensated by primary aluminium (implying a demand rather than supply driven market), the avoided impact would be reduced accordingly. The results assume similar mechanical properties for the products obtained by the solid state recycling routes and their respective conventional reference products. Enhanced mechanical properties, as indicated by Table 1 , can lead to further impact reductions.

Fig. 4 presents the environmental burden for the medium scenario (10\% metal losses) according to the midpoint impact categories with labelling for the four most important ones. The near net shaping capabilities of the SPS process were not taken into account in this comparative LCA since the post processing operations that can be avoided or reduced depend severely on the targeted part geometry. If the scope of the studied process chain were to be extended to include the full series of manufacturing operations, the achievable impact reduction would be larger as result of avoided or reduced material removal operations and the corresponding material recycling activities.

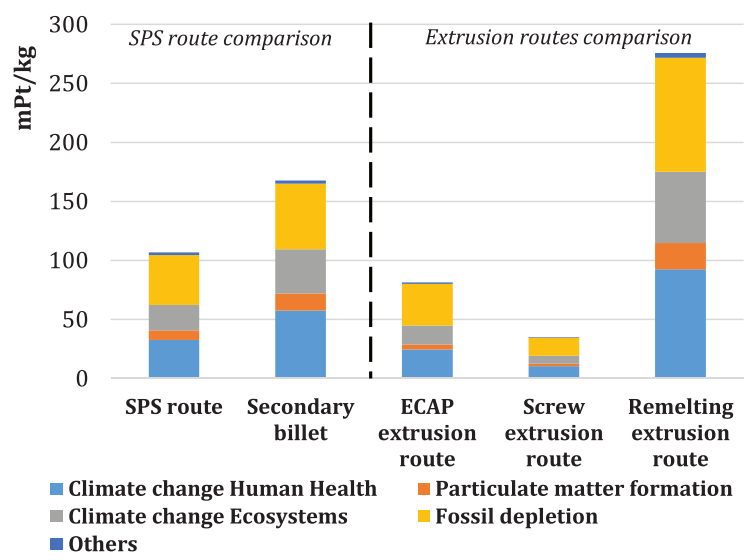

Fig. 4. Impact assessment results for the medium scenario (10\% metal losses) according to the main midpoint impact categories.

\section{Conclusions and outlook}

Although still mainly based on observations in experimental settings, the potential for significant environmental impact reduction offered by the respective analysed solid state recycling methods for production scrap can be clearly demonstrated. Reductions with a factor 2-4 were documented for the extrusion processes when considering average industrial material loss fractions for the studied recycling processes. For SPS, depending on the severity of the oxidation losses, up to a factor 2.5 could be realized for turnings (material losses of $16 \%$ or higher). However, when processing production scrap streams with higher metal recovery yield during remelting, the impact reduction is limited for this route. The environmental impact of SPS is highly determined by the electrical energy consumption per unit mass. To reduce this value, strategies could be the production of large or multiple small products, shorter sintering cycles and improved energy efficiency of the process itself. The actual impact reduction also depends on the near net shaping capabilities of the SPS process compared to billet casting, a consideration not taken into account in this comparative LCA. Also the possibilities to deliver improved mechanical properties were not considered. The impact reduction improvement of SPS as obtained from this study can therefore be considered a lower limit for the actual potential.

Avoided material losses and reduced energy consumption are the major elements explaining the significant impact reductions obtained. This is a fortiori true for scrap types with a high surfaceto-volume ratio due to the important avoided material losses caused by heavy oxidation in the conventional remelting route.

However, in solid state scrap processing, composition readjustments and impurity removal are not feasible as in remelting. This imposes additional constraints in scrap handling and sorting: it is crucial to process scrap in single alloy loops, thus avoiding the accumulation of impurities and alloy mixing. By minimising composition uncertainties the final product quality can be assured. Uncoated process scrap from wrought aluminium alloys, mainly in form of light-gauge scrap ( 20\% [19]), and also other forms (e.g. sheet metal scrap or shredded scrap) are suitable to be processed by solid state recycling.

Scaling up the processes described could allow further efficiency improvements. The screw extrusion already indicates that a continuous process variant offers major advantages in this respect. Improved energy efficiency is currently the focus of ongoing research and allows to anticipate a further increase of the impact reductions. This offers perspectives for industrial development of solid state recycling processes as environmentally benign alternatives for the current melting based practices.

\section{References}

[1] Boin UMJ, Bertram M (2005) Melting Standardized Aluminium Scrap: A Mass Balance Model for Europe. JOM: Journal of the Minerals Metals and Materials Society 57(8):26-33.

[2] Paraskevas D, Kellens K, Dewulf W, Duflou JR (2014) Environmental Modelling of Aluminium Recycling: A Life Cycle Assessment Tool for Sustainable Metal Management. Journal of Cleaner Production. http://dx.doi.org/10.1016/j.jclepro.2014.09.102.

[3] EAA - European Aluminium Association (2008) Environmental Profile Report for the European Aluminium Industry. Life Cycle Inventory Data for Aluminium Production and Transformation Processes in Europe.

[4] Milford RL, Allwood JM, Cullen JM (2011) Assessing the Potential of Yield Improvements, Through Process Scrap Reduction, for Energy and $\mathrm{CO}_{2}$ Abatement in the Steel and Aluminium Sectors. Resources Conservation and Recycling 55(12):1185-1195

[5] International Aluminium Institute (2014) Global Mass Flow Model 2012. Available at: http://www.world-aluminium.org/publications/.

[6] Xiao Y, Reuter MA (2002) Recycling of Distributed Aluminium Turning Scrap. Minerals Engineering 15(11, Suppl. 1):963-997.

[7] Van Geertruyden WH, Prescott CA, Misiolek WZ, Peterson R (2005) Evaluation of Light Gauge Al Scrap Remelting After Consolidation via the Extrusion Process. Light Metal Age 63(N6):14-18.

[8] Cooper DR, Allwood JM (2014) The Influence of Deformation Conditions in Solid-State Aluminium Welding Processes on the Resulting Weld Strength. Journal of Materials Processing Technology 214:2576-2592.

[9] Stern, M., 1945. U.S. Patent 2,391,752.

[10] Misiolek WZ, Haase M, Khalifa NB, Tekkaya EA, Kleiner M (2012) High Quality Extrudates from Aluminum Chips by New Billet Compaction and Deformation Routes. CIRP Annals - Manufacturing Technology 61(1):239-242.

[11] Tekkaya AE, Schikorra M, Becker D, Biermann D, Hammer N, Pantke K (2009) Hot Profile Extrusion of AA-6060 Aluminum Chips. Journal of Materials Processing Technology 209:3343-3350.

[12] Haase M, Khalifa BN, Tekkaya EA, Misiolek WZ (2012) Improving Mechanical Properties of Chip-Based Aluminum Extrudates by Integrated Extrusion and Equal Channel Angular Pressing. Materials Science and Engineering A 539:194-204.

[13] Widerøe F, Welo T (2013) Journal of Materials Processing Technology 213(7):1007-1018

[14] Paraskevas D, Vanmeensel K, Vleugels J, Dewulf W, Deng Y, Duflou JR (2014) Spark Plasma Sintering As a Solid-State Recycling Technique: The Case of Aluminum Alloy Scrap Consolidation. Materials 7(8):5664-5687.

[15] Kellens K, Dewulf W, Overcash M, Hauschild M, Duflou JR (2011) Methodology for Systematic Analysis and Improvement of Manufacturing Unit Process Life Cycle Inventory. International Journal of Life Cycle Assessment 17(1):69-78.

[16] Granta's CES EduPack: Teaching Resources for Materials and Process Education. Available online: http://www grantadesign.com/education/.

[17] Ecoinvent (2012) Ecoinvent Database v2.2, Swiss Centre for Life Cycle Inventories, Duebendorf, Switzerland. Available at: http://www.ecoinvent.ch/.

[18] Mashhadi HA, Moloodi A, Golestanipour M, Karimi EZV (2009) Recycling of Aluminium Alloy Turning Scrap via Cold Pressing and Melting With Salt Flux. Journal of Materials Processing Technology 209/7:3138-3142.

[19] Güley V (2014) Recycling of Aluminium by Hot Extrusion, Shaker Verlag, Aachen115. IUL (PhD Thesis), ISBN 978-3-8440-2476-0. 